\title{
Understanding an Extension Technology Acceptance Model of Google Translation: A Multi-Cultural Study in United Arab Emirates
}

\author{
https://doi.org/10.3991/ijim.v14i03.11110 \\ Rana Saeed Al-Maroof \\ Al Buraimi University College, Al Buraimi, Oman \\ Said A. Salloum ${ }^{(凶)}$ \\ University of Sharjah, Sharjah, UAE. \\ The British University in Dubai, Dubai, UAE \\ ssalloumesharjah.ac.ae \\ Ahmad Qasim Mohammad AlHamadand \\ Abu Dhabi University, Abu Dhabi, UAE \\ Khaled Shaalan \\ The British University in Dubai, Dubai, UAE
}

\begin{abstract}
The importance of using Google Translate (GT) has become dominantly more effective. Most researchers, professors, and students rely on its translation as an immediate source of getting information in different countries all over the world. However, previous studies failed to cover these influential factors that pinpoint the relation between GT and user's intention, and consequently fail to discover the effects of using GT. The purpose of this study is to explore GT acceptance in United Arab Emirates (UAE). It is assumed that users' attitude towards GT may vary based on the language used. The variations in languages are unidirectional where at least two languages are involved in this process. The suggested analytical framework is based on an extended TAM model. A quantitative methodology approach was adopted in this study. The hypothesized model is validated empirically using the responses received from a survey of 368 respondents, which were analyzed using structural equation modeling (SEM-PLS). Results indicated that Perceived Ease of Use, Perceived Usefulness, and Motivation have a significant impact on Behavioral Intention to use GT. In addition, Perceived Usefulness and Motivation significantly influenced Perceived Ease of Use. Furthermore, Perceived Usefulness is in turn influenced by Experience. The findings provide significant theoretical and practical implications for translation researchers, teachers, and machine translation system developers.
\end{abstract}

Keywords - Google Translate $\odot$, Acceptance Model, Source and Target Languages, Cultural Differences, UAE. 


\section{Introduction}

The study of technology acceptance is one of the widely-spread issues that has been the concern of many researchers recently. Machine translation (henceforth MT) and, in particular, Google translate (henceforth GT) is one of the widely-used translation technology. Thus, the acceptance of such technology is a critical issue that needs further investigation. MT is an influential instrument that affects users who are intended to translate a particular text from one language to another. It facilitates the speaking and written mode of communication in multi-lingual groups and helps in liberating members from the language barrier. However, such technology will be unable to motivate and satisfy its users when it fails to send the message from a speaker to an addressee conveying the same intended meaning. This is due to the variations between the source language (SL) to target language (TL) that do not yield the original expression. In such a context, the addressee cannot echo the speaker's expression as a way of accepting it, illustrating that they are referring to the same thing [1].

Within these variations among speakers and addressee, a study that shows the acceptance of GT is required. To be able to measure the acceptance of GT, TAM acceptance model is used. TAM is a widely spread model that intends to investigate user acceptance. The model has key variable including perceived usefulness, perceived ease of use, and behavioural intention. These variables can explain the users' behaviour intention to use technology [2]. It is considered the key factor that helps technology developer to be acquainted with the different environment to evaluate and investigate an information system [3]. TAM was proposed on the basis of cognitive beliefs of perceived usefulness and perceived ease of use [4]. Other variables that are related to TAM are the belief, attitude, and intention to use. TAM has influenced the user's behavioural intentions and attitude either directly or indirectly in order to assess the user's actual use of the technology [4]-[6]. The relevance of TAM to measure the acceptance of using GT and its strong impact on the users' acceptance is evident. The variable ease of use and perceived usefulness can influence users' acceptance of the technology.

Despite the fact that TAM has a strong impact on technology acceptance, there are certain factors that should be added to make the model of the study more comprehensive, namely: experience and motivation. Some researchers believe that experience is connected with TAM variable perceived ease of use. Experience impacts positively the readiness to accept technology along with cultural values, personality and technological background [7]. Experience has been connected with utility. These two terms have two different implications within technology acceptance/adoption. Experience refers to the early-period of usage, whereas utility refers to long term utility. Both of them are crucial in developing users' acceptance of technology [8]. Similarly, motivation especially hedonic motivation is meant to have an influence on the behavioural intention to use a product [9]. Hedonic motivation usually refers to the notion of fun or pleasure that is created because of using technology. Thus, it is considered a dominant element that increases behavioural intention to use it [10], [11]. Furthermore, variations in culture may have its own impact in this study. The acceptance of GT 
may vary from one group to another in UAE. Variations in nationality entail differences in the SL and TL; thus, it paves the way to a crucial issue which is language and structural variations across different languages. The difference in the grammatical and semantic structures from the SL to TL may result in different levels of clarity in the translated texts; thus, affecting the intention to use the technology and the perceived usefulness. The cultural aspect determines how people use technology since they might have different perceptions about it and use it in different cultural circumstances [1]. Therefore, it is essential to conduct a cross-cultural study of GT acceptance.

This study has two gaps that are uncovered in previous studies. The first gap is to build a comprehensive model that is able to measure the main variables that affect users' acceptance of GT. These variables are related to the social, cultural and psychological factors, and they have direct connection with the technology itself and encourages users to intentionally use it. Thus, this study is an attempt to provide answer to the gap found in the literature by incorporating experience and motivation into the original TAM to develop an extended quasi-circular model. The second gap is related to the variations in culture. Variations in structures of SL and TL is highly effective in measuring users' intention or behaviour towards the usage of GT as well as the cultural differences which may affect the user's acceptance of the technology. To the best of our knowledge, no such research has been conducted in the context of GT acceptance in different countries. Most studies, as explained in the previous paragraphs, have examined the acceptance of MT in a single country's acceptance. The objective of this study is to define what drives the acceptance of GT by Omani, Pakistani, and the UAE citizens. This approach of research enables to pinpoint the variable that has a strong impact on using technology. Cultural variations give us the opportunity to measure and compare the user's behavioural intention in different countries.

\section{$2 \quad$ Literature Review}

\subsection{TAM \& user acceptance of machine translation quality of the system}

The related literature has focused on the possibilities of applying MT in general such as [12], who propose an extended TAM model to measure users' acceptance of MT. The study has analyzed the extended model associated with the behavioral use of MT on the basis of TAM. [13] carries out a similar study where the focus is on the Neural Machine Translation. The main results indicate that the majority of students use NMT to support their language studies for a variety of purposes. Generally, the results have shown disparities among students in terms of their dependency upon and perceived value of such tools. Another study is conducted by [14] shows how the priorities and aspirations articulated. Thus, the source can be operationalised using translation technology classroom and lab. They planned to create an SMT syllabus for a group of postgraduate translation students to figure out how data are derived from a mixed-methods approach. The results have shown that there is noteworthy interest on the part of students to improve their knowledge of and confidence in using machine translation in general and SMT in particular. This is conditioned with the completion 
of teaching units in SMT. The last study [15] highlights the aspects of MT in a systematic review. It comes up with a quantitative and qualitative description of MT research in its systematic review.

\subsection{Experience and motivation and acceptance of technology}

Previous studies on experience and motivation in measuring acceptance of technology are varied. [7] state that there is a direct relation between the successfulness in using technology and experience. Users will be able to give response better when their experience is higher. Therefore, experience is considered as a determinant factor in getting feedback from users and it seems to be related to a time period. A similar attitude is given by [16] who highly evaluate experience in environment where Moodle is used. They stated that the higher the experience in using Moodle is, the more effective the results will be. Some researchers suggest that investigating experience within longitudinal studies have a strong impact on users intention to accept the technology because the investigation of the effectiveness of experience, utility, hedonic qualities and usability may vary over a period of time. A study by [17] suggests a distinction between users experience (UX) and experience (E). User experience is more important than job experience because it is connected with user cognition, actions and product. Therefore, a connection can be made between poor usability experience and rejection of technology. Users who do not have the required usability experience tend to reject using the technology.

Literature review seems to be in favor of connecting experience with other important variables that make the measurement of experience more practical and efficient. Thus, a connection can be drawn between experience and anxiety on one hand and experience and self-efficiency on the other hand. According to [18], users, who have high level of experience, will have less degree of anxiety in using the technology. Similarly, self-efficiency has a direct relation with attitude, ease of use and usefulness. The higher the efficiency is, the higher the experience and the acceptance will be [19]-[22]. A similar conception is made between motivation which is considered as an external factor and other TAM variables. Studies on motivation seems to integrate motivation with TAM variables. A study by [23] proposes a connection between motivation and perceived playfulness. Motivation can be created when the level of playfulness is high. This encourages users to accept and use the technology. Another study tackles the concept of motivation from different perspective where motivation is connected with cultural and competence aspects [24]. In this study, the users' motivation is higher under two conditions. The first one is: when his feeling of belonging is high and the second one is: when the users autonomous and competence is high. In agreement with the previous studies, some studies have considered the lack of experience and motivation as a crucial factors in rejecting the technology [8].

\subsection{Cultural variations and technology acceptance}

Users from different backgrounds with different diverse value orientations may not have similar reaction to technology acceptance. This is due to the fact that they have 
different attitudes towards cultural differences and individual thinking [25]. Taking into consideration this fact, culture has an impact on the acceptance/rejection of technology. Recent studies by [26] and [27], have shown that people from different background may act differently to technology acceptance and that TAM is irrelevant to studies of culture for different reasons. For [26], differences are found between Lebanese and British university students. They found that the relationship between Perceived Usefulness (PU) and that Perceived Ease of Use (PEU) was positively evaluated by the British sample only. They concluded that TAM is biased in cross-cultural contexts. A similar conclusion is given by [27] as they state that PEU, which is an influential factor in TAM, has no significant role in users' acceptance of technology.

On the other hand, other studies seem to evaluate culture aspect rather differently. A study by [28] confirms the role of culture and its impact on attitude and individual thinking. Culture seems to be an influential factor because it has impact on innovation and willingness which implies that culture can be considered as a factor in technology acceptance. Finally, it seems that there are two different perspectives towards the effectiveness of culture in technology acceptance. One perspective seems to lessen the role of culture and the other puts more emphasis on it due to the fact that it affects other factors.

\section{Research Model and Hypotheses}

Google translation facility is a web-based technology that is accessible by a vast number of users worldwide. This study focuses on the acceptance of usage of GT by teachers, students, scholars and researchers in three different countries. GT is one tool under MT. They can produce a text within a short period as they can depend on a simple process of cut and paste. Accordingly, it is assumed that this technology is affected by the PEU and PU. Consequently, it is assumed that PEU may have a 12 great impact on the intention to use MT [12].

Motivation and Experience are two variables that have a close relation with technology acceptance. According to [12], motivation has a close relation with PEU. Based on that, they state that the higher level of PEU is, the stronger the motivation will be. Whenever there is a high tendency to learn more about translation studies and process, the higher to explore in MT. However, this study does not focus on students' motivation in learning translation, but rather on the user's motivation in using the GT translation technology as a tool more heavily and frequently. That is, whenever the translated texts are clearly translated and the intended meaning is given obviously, the higher the motivation will be in using GT rather than any other MT tools. According to [29], experience affects students' eagerness to use technology. The higher the experience is the greater the perceived usefulness towards technology. In this respect, [12] proposes that when the student are well-acquainted with MT, they can appreciate the pros of using MT and they gradually become more professional in using MT for academic purposes. Based on that, the following hypotheses are formed:

- Hypothesis 1: Perceived Ease of Use has a positive effect and great impact on the Behavioral Intention to use GT. 
- Hypothesis 2: Perceived Usefulness has a positive effect and great impact on the Behavioral Intention to use GT.

- Hypothesis 3: Perceived Ease of Use has a positive effect and substantial impact on the Perceived Usefulness.

- Hypothesis 4: Experience has a positive effect and substantial impact on the Perceived Usefulness.

- Hypothesis 5: Perceived Ease of Use has a positive effect and great impact on Motivation when MT is used as a tool.

- Hypothesis 6: Motivation can positively and significantly affect Experience in using GT.

It is worth to mention that this model eliminates attitude as many researchers proposed that establishing a direct relation between Perceived Essay of Use and Perceived Usefulness may bring better results on Behavioral Intention (cf. [30] and [31].

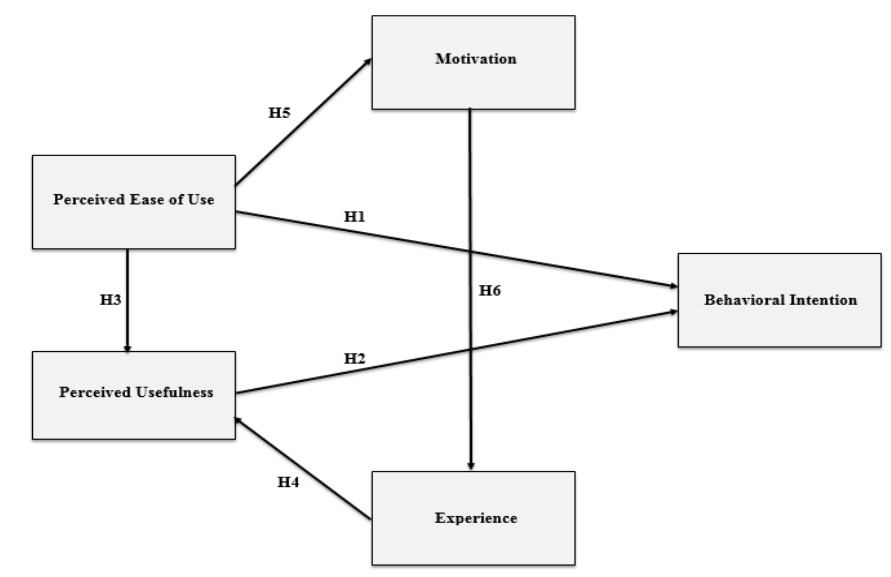

Fig. 1. The study model

\section{$4 \quad$ Research Methodology}

\subsection{Measurement of constructs}

To be able to test the proposed hypotheses, a survey was conducted that incorporates all the constructs involved in the proposed model. All items were formed based on the main critical points in the hypotheses. The details of the items are listed in Appendix (A). 


\subsection{Research method}

To explore the acceptance of GT as a technology, we followed specific guidelines that help in practically measuring the acceptance or rejection. The main steps can be summarized as follows:

- Proposing a model that incorporates TAM and other variables to investigate the acceptance of GT.

- Distributing hard copies of questionnaire with set of questions that are related to the proposed hypotheses.

- The results are analyzed and synthesized, reported in the result section.

\subsection{Sample and data collection}

The hard-copy surveys were distributed amongst the students in the United Arab Emirates (UAE), data was gathered between 07-April-2019 and 24-April-2019 during the winter semester of the academic year 2018/2019. The number of randomly distributed questionnaires was 400, against which the respondents had reacted to 368 questionnaires that made up a total response rate of $92 \%$. In addition, certain missing values led to the rejection of 32 of these filled questionnaires. Hence, the team considered 368 as properly filled and effective questionnaires. According to [32], overall 368 valid responses were collected with appropriate sample size level, i.e., the projected sampling size for a population of 1500 in 306 respondents. Compared to insignificant requirements, a sample size of 368 is way higher. Therefore, the assessment with structural equation modeling is acceptable as a sample size [33], which was subsequently employed for confirming the hypotheses. Most importantly, hypotheses were established on the basis of existing theories, but they were also accommodated to the Mobile-learning context. The team of researchers' utilized structural equation modeling (SEM) (with SmartPLS Version 3.2.7 tool) to evaluate the measurement model. The final path model was used for the advanced treatment.

\subsection{Pilot study of the questionnaire}

The reliability of the questionnaire items was evaluated through a pilot study. Almost 40 students randomly selected from the decided population constituted this pilot study. Based on $10 \%$ of the total sample size of this analysis, the sample size was decided with (400 students) and the research standards were carefully followed in this regard. To evaluate the findings of the pilot study, Cronbach's alpha test was used for internal reliability with the help of SmartPLS, as a result of which acceptable conclusions were illustrated for the measurement items. A reliability coefficient of 0.70 is assumed to be acceptable, if we emphasize on the mentioned pattern of social science research studies [34]. The Cronbach alpha values for the following 7 measurement scales are given in Table 1. 
Table 1. Cronbach's Alpha values for the pilot study (Cronbach's Alpha $\geq 0.70$ ).

\begin{tabular}{|l|c|}
\hline \multicolumn{1}{|c|}{ Construct } & Cronbach's Alpha \\
\hline Behavioral intention & 0.889 \\
\hline Experience & 0.827 \\
\hline Motivation & 0.832 \\
\hline Perceived ease of use & 0.922 \\
\hline Perceived Usefulness & 0.798 \\
\hline
\end{tabular}

\subsection{Survey structure}

The paper is based on using three different instruments to implement the data empirically. In other words, the three parts embrace the following factors which are: Demographic information, Technology Acceptance Questionnaire, and Motivation in using Google Translation Questionnaire. Demographic information is devoted to information about participants' age, gender and experience in using GT. Technology Acceptance Questionnaire is adopted from the extended model of TAM that is proposed by [12]. It aims at evaluating users' intention to use GT. It includes (3) items measuring users' Perceived Ease of Use and (3) items for Perceived Usefulness and (3) items for measuring the Behavioral Intention. The items are measured based on five-point Likert-type from "strongly disagree=1" to "strongly agree=5". Most of the items are modified to suit our aims concerning GT use in different countries.

For the sake of clarity, the questionnaire has been translated into Arabic in Oman to guarantee that users evaluate the intended questions clearly and the meaning is widely comprehended.

\subsection{Students' personal information/demographic data}

Students ration is varied based on the male and female distinction with percentage of $63 \%$ for male and $37 \%$ for female. For $72 \%$ of the respondents, student's age was found between 18 and 29 years while the respondents who were above 29 were $28 \%$. As far as the academic background is concerned, the students belonging to Business Administration were 35\%, while students in Information Technology, Engineering, Arts, Social Sciences \& Humanities and Mass Communication and Public Relations were $23 \%, 21 \%, 11 \%$ and $10 \%$ respectively. Foregoing in view, the bachelor degree was owned by $53 \%$ individuals while $30 \%$ possessed a master degree, $17 \%$ of the respondents were having a doctoral degree while rest of the respondents were diploma holders. According to [35], the "purposive sampling approach" was employed when access to the respondents is easy and they are willing to volunteer. The students from different colleges made up this study sample; these students were having different ages; they were part of different programs at different levels. In addition, the demographic data was measured with the help of IBM SPSS Statistics ver. 23. 


\section{$5 \quad$ Findings and Discussion}

The partial least squares-structural equation modeling (PLS-SEM) was used to carry out the data analysis in this study [36]. A two-step assessment approach including the structural model and measurement model was employed to analyze the collected data [37]. There are several reasons for the selection of PLS-SEM in this study. First, PLS-SEM is believed to be an ideal choice when the research scholars are going to establish an existing theory [38]. Secondly, exploratory studies containing complex models can ideally be served by the PLS-SEM [39]. Thirdly, instead of splitting it into pieces, the complete model is analyzed as one unit in PLS-SEM [40]. Fourthly, for both structural model and measurement, concurrent analysis is provided by PLSSEM, which subsequently results in clear-cut and precise estimations [41].

\subsection{Assessment of the measurement model (Outer model)}

Convergent validity: According to [37], to assess the measurement model, estimation of the construct reliability (composite reliability and Cronbach's alpha) and validity (discriminant and convergent validity) was proposed. To determine the construct reliability, the values of Cronbach's alpha in Table 2 are illustrated between 0.729 and 0.834 and the threshold value of 0.7 falls underneath these values [42]. As per the findings of Table 2, the composite reliability (CR) yields in the values between 0.723 and 0.898 , which were found above the suggested value of 0.7 [43]. Consistent with these findings, all the constructs were considered to be error-free and the construct reliability is established. The average variance extracted (AVE) and factor loading need to be tested for the measurement of convergent validity [37]. As per Table 1, all factor loadings were having the values above the suggested value of 0.7 . Moreover, Table 2 is also indicative of the fact that the AVE yields in the values between 0.539 and 0.712 , which were found above the threshold value of 0.5 . Subject to these results, the researchers have adequately satisfied the convergent validity for all constructs.

Discriminant validity: Three criteria, namely: the cross-loadings, Fornell-Larker criterion, and the Heterotrait-Monotrait ratio (HTMT) were suggested to be measured for the measurement of discriminant validity [37]. As per the findings of Table 3, the requirements are confirmed by the Fornell-Larker condition, since all AVEs along with their square roots are greater than its correlation with other constructs [44]. Table 5 and its results also fulfill the cross-loadings standard, since the indicator loadings on each construct are higher than the loadings of its corresponding constructs. The HTMT ratio results are given in Table 4, which is representative of the fact that the threshold value of 0.85 remains ahead of the value of each construct [45]. Hence, the HTMT ratio is established. The discriminant validity is determined according to these findings. In line with the analysis results, no issues were emerged regarding the assessment of the measurement model with respect to its validity and reliability. Therefore, the structural model can be evaluated with the further utilization of the collected data. 
Table 2. Convergent validity results which assures acceptable values (Factor loading, Cronbach's Alpha, composite reliability $\geq 0.70 \&$ AVE $>0.5)$.

\begin{tabular}{|c|c|c|c|c|c|}
\hline Constructs & Items & Factor Loading & Cronbach's Alpha & $\mathbf{C R}$ & AVE \\
\hline \multirow[t]{3}{*}{ Behavioral intention } & BI1 & 0.836 & \multirow{3}{*}{0.834} & \multirow{3}{*}{0.723} & \multirow{3}{*}{0.539} \\
\hline & $\mathrm{BI} 2$ & 0.856 & & & \\
\hline & $\mathrm{BI} 3$ & 0.936 & & & \\
\hline \multirow[t]{3}{*}{ Experience } & EXP1 & 0.806 & \multirow{3}{*}{0.799} & \multirow{3}{*}{0.765} & \multirow{3}{*}{0.619} \\
\hline & EXP2 & 0.812 & & & \\
\hline & EXP 3 & 0.839 & & & \\
\hline \multirow[t]{3}{*}{ Motivation } & MOT1 & 0.772 & \multirow{3}{*}{0.729} & \multirow{3}{*}{0.883} & \multirow{3}{*}{0.551} \\
\hline & MOT2 & 0.789 & & & \\
\hline & MOT3 & 0.855 & & & \\
\hline \multirow[t]{3}{*}{ Perceived ease of use } & PEOU1 & 0.896 & \multirow{3}{*}{0.830} & \multirow{3}{*}{0.898} & \multirow{3}{*}{0.666} \\
\hline & PEOU2 & 0.848 & & & \\
\hline & PEOU3 & 0.776 & & & \\
\hline \multirow[t]{3}{*}{ Perceived Usefulness } & PU1 & 0.890 & \multirow{3}{*}{0.829} & \multirow{3}{*}{0.756} & \multirow{3}{*}{0.712} \\
\hline & PU2 & 0.759 & & & \\
\hline & PU3 & 0.837 & & & \\
\hline
\end{tabular}

Table 3. Fornell-Larcker Scale

\begin{tabular}{|l|c|c|c|c|c|}
\hline & BI & EXP & MOT & PEOU & PU \\
\hline BI & 0.881 & & & & \\
\hline EXP & 0.369 & 0.804 & & & \\
\hline MOT & 0.434 & 0.312 & 0.915 & & \\
\hline PEOU & 0.581 & 0.405 & 0.339 & 0.857 & \\
\hline PU & 0.448 & 0.389 & 0.528 & 0.447 & 0.889 \\
\hline
\end{tabular}

Table 4. . Heterotrait-Monotrait Ratio (HTMT)

\begin{tabular}{|l|c|c|c|c|c|}
\hline & BI & EXP & MOT & PEOU & PU \\
\hline BI & & & & & \\
\hline EXP & 0.551 & & & & \\
\hline MOT & 0.671 & 0.567 & & & \\
\hline PEOU & 0.634 & 0.510 & 0.358 & & \\
\hline PU & 0.489 & 0.564 & 0.256 & 0.257 & \\
\hline
\end{tabular}

Table 5. Cross-loading results

\begin{tabular}{|l|c|c|c|c|c|}
\hline & BI & EXP & MOT & PEOU & PU \\
\hline BI1 & $\mathbf{0 . 8 3 6}$ & 0.305 & 0.278 & 0.483 & 0.469 \\
\hline BI2 & $\mathbf{0 . 8 5 6}$ & 0.358 & 0.322 & 0.298 & 0.207 \\
\hline BI3 & $\mathbf{0 . 9 3 6}$ & 0.521 & 0.557 & 0.299 & 0.310 \\
\hline EXP1 & 0.398 & $\mathbf{0 . 8 0 6}$ & 0.287 & 0.291 & 0.239 \\
\hline EXP2 & 0.444 & $\mathbf{0 . 8 1 2}$ & 0.309 & 0.327 & 0.589 \\
\hline EXP 3 & 0.456 & $\mathbf{0 . 8 3 9}$ & 0.236 & 0.365 & 0.673 \\
\hline MOT1 & 0.401 & 0.673 & $\mathbf{0 . 7 7 2}$ & 0.398 & 0.364 \\
\hline MOT2 & 0.488 & 0.506 & $\mathbf{0 . 7 8 9}$ & 0.277 & 0.335 \\
\hline MOT3 & 0.538 & 0.535 & $\mathbf{0 . 8 5 5}$ & 0.178 & 0.233 \\
\hline
\end{tabular}




\begin{tabular}{|l|l|l|l|l|l|}
\hline PEOU1 & 0.558 & 0.436 & 0.288 & $\mathbf{0 . 8 9 6}$ & 0.390 \\
\hline PEOU2 & 0.432 & 0.324 & 0.286 & $\mathbf{0 . 8 4 8}$ & 0.576 \\
\hline PEOU3 & 0.436 & 0.382 & 0.694 & $\mathbf{0 . 7 7 6}$ & 0.550 \\
\hline PU1 & 0.492 & 0.233 & 0.456 & 0.369 & $\mathbf{0 . 8 9 0}$ \\
\hline PU2 & 0.585 & 0.221 & 0.502 & 0.394 & $\mathbf{0 . 7 5 9}$ \\
\hline PU3 & 0.586 & 0.477 & 0.367 & 0.446 & $\mathbf{0 . 8 3 7}$ \\
\hline
\end{tabular}

\subsection{Assessment of structural model (inner model)}

Coefficient of determination - $\mathbf{R}^{2}$ : By utilizing the coefficient of determination $\left(\mathrm{R}^{2}\right.$ value) measure, the research team usually inspect the structural model, see [46] and [47]. This coefficient is processed as the squared correlation between a specific endogenous construct's actual and predicted values and we can measure the predictive accuracy of the model through this coefficient, see [48] and [49]. The coefficient is indicative of the exogenous latent variables' joined effect on an endogenous latent variable. As discussed earlier that the coefficient is the squared correlation. Hereafter, it supplements the implication of variance degree in the endogenous constructs. Each exogenous construct secures this point and it also assists in finding it. As declared by [50], once the value is above 0.67 , it is seen as high. This is suggestive of the fact that the qualities in the scope of 0.19 to 0.33 are weak values and those in the scope of 0.33 to 0.67 are direct. Additionally, estimation is inadmissible when it is below 0.19 . As depicted in Table 6 and Figure 2, the $\mathrm{R}^{2}$ values for experience, motivation and perceived usefulness were found to be between 0.33 and 0.67 ; and hence, the predictive power of these constructs is considered as moderate. Besides, the $\mathrm{R}^{2}$ value of the behavioral intention use is found to explain $70.7 \%$ of the variance, and, therefore; the predictive power of this construct is considered as high.

Table 6. $\mathrm{R} 2$ of the endogenous latent variables

\begin{tabular}{|l|c|l|}
\hline \multicolumn{1}{|c|}{ Constructs } & \multicolumn{1}{c|}{$\mathbf{R}^{\mathbf{2}}$} & \multicolumn{1}{c|}{ Results } \\
\hline Behavioral Intention & 0.707 & High \\
\hline Experience & 0.684 & Moderate \\
\hline Motivation & 0.567 & Moderate \\
\hline Perceived Usefulness & 0.523 & Moderate \\
\hline
\end{tabular}

Goodness of fit of the model: The study model is basically measured on two scales using the Goodness of fit of the model $(\mathrm{GoF})$, the structural model and the measurement, and can be determined as follows to ensure the reliability of the model in the whole GoF. GoF referred to the Global fit measure, according to [51], which means the geometric mean of average variance extracted (AVE) and the endogenous factors of the $\mathrm{R}^{2}$ average [48].

$$
\mathrm{GoF}=\sqrt{\left.\overline{\left(\mathrm{R}^{2}\right.} \times \overline{\mathrm{AVE}}\right)}
$$


GoF's parameters have been proposed [52] in order to determine one of the three categories based o: small, medium or large, which can be interpreted as a legitimate globally accepted PLS model. Those parameters are mentioned in Table 7.

Table 7. The criteria of Gof

\begin{tabular}{|l|l|}
\hline \multicolumn{1}{|c|}{ GoF } & \multicolumn{1}{|c|}{ Result } \\
\hline Greater than 0.36 & Large \\
\hline Between 0.25 to 0.36 & Medium \\
\hline Less than 0.1 to 0.25 & Small \\
\hline Less than 0.1 & No fit \\
\hline
\end{tabular}

Table 8. .Goodness of Fit of the model (GoF)

\begin{tabular}{|c|c|}
\hline \multicolumn{1}{|c|}{ Constructs } & AVE \\
\hline Perceived ease of use & 0.666 \\
\hline Perceived Usefulness & 0.712 \\
\hline \multicolumn{1}{|c|}{ Constructs } & $\mathbf{0 . 6 8 9}$ \\
\hline Average & $\mathbf{R}^{\mathbf{2}}$ \\
\hline Behavioral Intention & 0.707 \\
\hline Experience & 0.684 \\
\hline Motivation & 0.567 \\
\hline Perceived Usefulness & 0.523 \\
\hline Average & $\mathbf{0 . 6 2 0}$ \\
\hline
\end{tabular}

The Gof model in the analysis is, therefore, very broad and demonstrates ample global PLS model validity. Table 8 above reveals that the Gof price is 0.654 .

Hypotheses testing: Once the measurement model is confirmed, the next step is the structural model. With the help of a bootstrapping procedure containing 5,000 resamples, this involves determining the path coefficients and the coefficient of determination (R2) [53]-[62]. With respect to path analysis, the path coefficients, t-values, and p-values for each hypothesis are shown in Table 5. Generally, all the hypotheses were supported. In that, the hypotheses H1, H2, H3, H4, H5, and H6 were supported by the empirical data. The results showed that Behavioral Intention to use GT (BI) significantly influenced Perceived Ease of Use (PEOU) $(\beta=0.716, \mathrm{P}<0.001)$, Perceived Usefulness (PU) $(\beta=0.637, \mathrm{P}<0.001)$, and Motivation (MOT) $(\beta=0.284$, $\mathrm{P}<0.001)$ supporting hypothesis $\mathrm{H} 1, \mathrm{H} 2$, and $\mathrm{H} 6$ respectively. Furthermore, the effect of Perceived ease of use (PEOU) and Experience (EXP) have a positive impact on Perceived Usefulness (PU) $(\beta=0.249 ; \mathrm{P}<0.05),(\beta=0.350 ; \mathrm{P}<0.05)$, respectively, were found to be not significant; hence, $\mathrm{H} 3$ and $\mathrm{H} 4$ is supported. The relationships between Perceived Ease of Use (PEOU) and Motivation (MOT) $(\beta=0.548, \mathrm{P}<0.05)$ was found to be statistically significant, and thus, the hypotheses H5 is generally supported. A summary of the hypotheses testing results is shown in Table 7. 
Table 9. Results of structural Model - Research Hypotheses Significant at $\mathrm{p}^{* *}=<0.01$, p* $<0.05$ Significant at $\left.\mathrm{p}^{* *}=<0.01, \mathrm{p}^{*}<0.05\right)$.

\begin{tabular}{|l|l|c|c|c|l|l|}
\hline \multicolumn{1}{|c|}{ H } & \multicolumn{1}{|c|}{ Relationship } & Path & $\boldsymbol{t}$-value & $\boldsymbol{p}$-value & Direction & \multicolumn{1}{|c|}{ Decision } \\
\hline H1 & $\begin{array}{l}\text { Perceived Ease of Use -> Behavioral } \\
\text { Intention to use GT }\end{array}$ & 0.716 & 23.315 & 0.000 & Positive & Supported** \\
\hline H2 & $\begin{array}{l}\text { Perceived Usefulness -> Behavioral Inten- } \\
\text { tion to use GT }\end{array}$ & 0.637 & 20.159 & 0.000 & Positive & Supported** \\
\hline H3 & $\begin{array}{l}\text { Perceived Ease of Use -> Perceived Use- } \\
\text { fulness }\end{array}$ & 0.249 & 6.736 & 0.015 & Positive & Supported* \\
\hline H4 & Experience -> Perceived Usefulness & 0.350 & 4.368 & 0.023 & Positive & Supported* \\
\hline H5 & Perceived Ease of Use -> Motivation & 0.548 & 2.106 & 0.013 & Positive & Supported* \\
\hline H6 & $\begin{array}{l}\text { Motivation -> Behavioral Intention to use } \\
\text { GT }\end{array}$ & 0.284 & 7.655 & 0.001 & Positive & Supported $* *$ \\
\hline
\end{tabular}

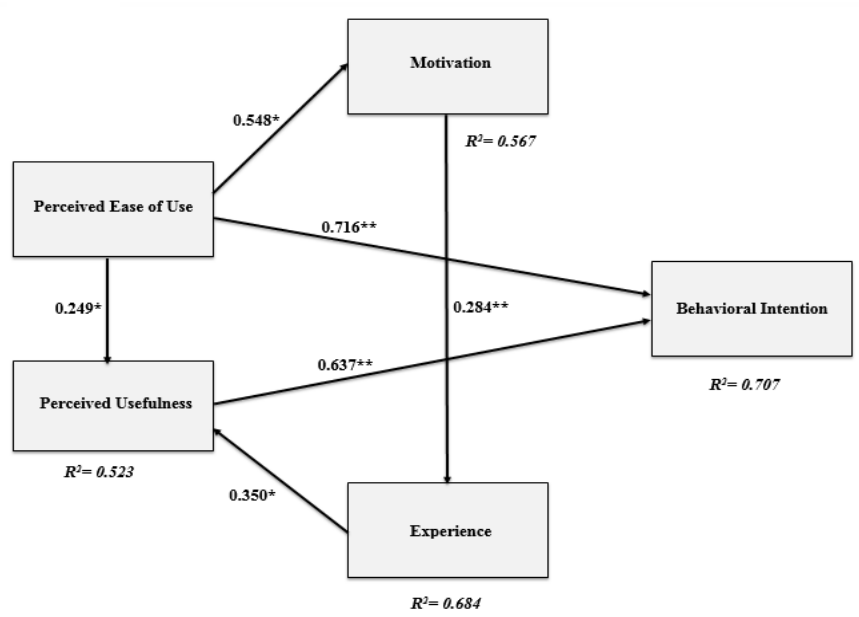

Fig. 2. Path coefficient results (significant at $\mathrm{p}^{* *}<=0.01, \mathrm{p}^{*}<0.05$ ).

\section{Discussion and Implication}

\subsection{Discussion of results}

This study adds to the existing literature on machine translation as educational technology. Although there have been a great number of studies on the TAM, few have focused on machine translation, especially Google Translate that facilitates both the spoken and written multi-lingual communication. The current study includes new external factors that seem to affect the acceptance or rejection of technology, namely: experience and motivation in addition to the aspects of usefulness and ease of use. Our outcomes can be stated as follows. First, TAM has proven to be an effective model on theoretical background. Second, ease of use, perceived usefulness and per- 
ceived ease of use have a positive impact on the acceptance of the technology. Consequently, educators and professors should urge their students to use technology. This implies that GT technology may work as a facilitator in implementing students' assignments and tasks. Likewise, technology developer should work hard to upgrade students' need in the future. These outcomes seem to go in line with the previous studies where they presumed that machine translation affects both the Perceived Ease of Use and Perceived Usefulness. Accordingly, the general belief is that Perceived Ease of Use may have a major impact on the intention to use MT [12].

Overall, the results show that motivation and experience are positively related to BI and PEOU and that PEOU and PU influence the intention to use GT (confirming our adapted TAM as a relevant theory). Three influential findings rise up as part of the results. First, the usage of GT has been increased recently and this builds up a high level of awareness among students and researchers to use it. These assumptions have been supported by previous research, such as [59] and [60]. The results indicate that Perceived Ease of Use and Perceived Usefulness are significant predictors of Behavioral Intention. These findings are in line with the previous studies, such as [1] and [61]. Furthermore, Perceived Usefulness is proved to be a stronger predictor as Perceived Ease of Use for Behavioral Intention. However, some studies on machine translation seem to reject using showing preferences in favor of prohibiting the use of MT in the classroom because it is ineffective [8]. A similar attitude is given by [9], who finds that there is a tendency to use online MT than using other free online resources.

The relation between the variable of usefulness in the TAM model and experience sheds the light on another important outcome. Experience can be measured more successfully when it is connected with usefulness. Increased usefulness encourages users to get more experience. Thus, they accept the technology and reach the satisfaction level. The result seems to agree with the previous study where they argue that the perceived usefulness is considered a concrete concept that can be measured in research, whereas experience tends to be more abstract and difficult to be interpreted [8]. Therefore, usefulness utility and functionality are important factors that support experience (See also [66]).

The conclusion that we can draw is that both usability and user experience affect tremendously users' judgments in accepting technology. We can argue that the focus on the factor of experience individually without taking into consideration the importance of usability, usefulness and functionality will lack crucial elements in measuring users' acceptance. The current study has also considered the relation between motivation and TAM. The outcomes of this study seem to be in line with previous studies by [63] and [64]. Similarly, the positive results that have been obtained concerning the positive role of motivation seem to agree with the previous studies, [65] and [66].

The final factor is culture where BI affects the three EXPs significantly. As it is shown, the results confirm that three groups of EXPs have almost the same perceptions in terms of GT acceptance. Furthermore, the results show two important similarities between the three RXP groups: (1) the strongest path of influence is BI which includes both PEOU and PU (See also [71]), and (2) PEOU are affected significantly 
by motivation. These results usually support the final assumption that users tend to share the same attitudes, regardless of their own native language and the intended target language. Accordingly, we can sum-up that culture has a strong impact on users' perceptions of GT. This seems to agree with the existing literature. One study suggests that culture should be taken into consideration in measuring technology acceptance [27]. Consequently, culture is not an independent factor but rather it should be connected to other variables, such as willingness, attitude, readiness and perceptions. That is why it is a crucial factor [72].

\subsection{Implications}

From a theoretical perspective, the present study focused on the importance of proposing a technology acceptance model to measure Google Translate acceptance in the UAE. It is considered a fundamental model to examine the acceptance of technology from the user perspective. This study also integrates two important aspects of technology which are experience and motivation in the technology acceptance model to have an inclusive awareness of technology acceptance. The impact of different cultural background in technology has been tackled previously by other researchers, such as [8], [67], [69], and [70]. However, the impacts of native language difference among a group of users, who share the same native language and the target language variations as far as Google Translate usage, have not been considered. Thus, the present study extends the technology acceptance model by including influential dimensions of technology acceptance by involving three different groups. They have different native languages; thus, their translation needs are different within the source and target language. The variations of language background among users, who live the UAE, have been ignored by other studies. In summary, the present study contributes to the literature by developing an extended technology acceptance model considering the impacts of variations in native languages at the individual level.

\subsection{Practical implications}

Based on the findings of the present study, it seems that users' perceived usefulness on their intention to use GT is extremely important to develop the GT software to meet the needs of users from different background cultures, as far as Experience and Motivation is concerned. To start with the former, Experience is intended to be a strong factor in the current study. Besides, Experience is considered an influential predictor of Perceived Usefulness. The great the experience is, the higher the perception. As for the latter, students' motivation towards using technology is affected by the Perceived Ease of Use. At the same time, it seems that motivation has affected the experience in a reciprocal manner where motivation could assist experience and vice versa. This type of circular relationship helps all educators and students to focus on the pedagogical aspects of motivation in creating a better learning environment. Focusing on the immediate accessibility of GT anywhere and anytime could provide good opportunities for learning and assist students' motivation. 


\subsection{Limitation and future research}

This study is limited to the application of model acceptance to a short snapshot to a group of individual in the UAE. Future studies can focus on longitudinal studies where usability, utility and ease of use can be assessed differently over a long period of time. Furthermore, this study focuses on UAE minority group, thus, future study should be applicable to similar Gulf area, such as Saudi Arabia, or even in Europe where there are more variations among group of users. Furthermore, this study has been implemented at two universities in the UAE. The applicability and pertinence of this study would have enhanced, whenever more institutes and universities in the UAE are considered.

\section{$7 \quad$ References}

[1] C. Hsu, Y.-T. Lin, and T. Wang, "A legitimacy challenge of a cross-cultural interorganizational information system," Eur. J. Inf. Syst., vol. 24, no. 3, pp. 278-294, 2015. https://doi.org/10.1057/ejis.2014.33

[2] R. Scherer, F. Siddiq, and J. Tondeur, "The technology acceptance model (TAM): A metaanalytic structural equation modeling approach to explaining teachers' adoption of digital technology in education," Comput. Educ., vol. 128, pp. 13-35, 2019. https://doi.org/10.1016/j.compedu.2018.09.009

[3] A. Revythi and N. Tselios, "Extension of Technology Acceptance Model by using System Usability Scale to assess behavioral intention to use e-learning," Educ. Inf. Technol., vol. 24, no. 4, pp. 2341-2355, 2019. https://doi.org/10.1007/s10639-019-09869-4

[4] Z. Hussein, "Leading to Intention: The Role of Attitude in Relation to Technology Acceptance Model in E-Learning," Procedia Comput. Sci., vol. 105, pp. 159-164, 2017. https://doi.org/10.1016/j.procs.2017.01.196

[5] S. A. Nikou and A. A. Economides, "Factors that influence behavioral intention to use mobile-based assessment: A STEM teachers' perspective," Br. J. Educ. Technol., vol. 50, no. 2, pp. 587-600, 2019. https://doi.org/10.1111/bjet.12609

[6] W. M. Al-Rahmi et al., "Integrating technology acceptance model with innovation diffusion theory: An empirical investigation on students' intention to use E-learning systems," IEEE Access, vol. 7, pp. 26797-26809, 2019. https://doi.org/10.1109/access.2019.2899368

[7] S. Sunny, L. Patrick, and L. Rob, "Impact of cultural values on technology acceptance and technology readiness," Int. J. Hosp. Manag., vol. 77, pp. 89-96, 2019. https://doi.org/10. $\underline{1016 / j . i j h m .2018 .06 .017}$

[8] J. Hart and A. Sutcliffe, "Is it all about the Apps or the Device?: User experience and technology acceptance among iPad users," Int. J. Hum. Comput. Stud., vol. 130, pp. 93-112, 2019. https://doi.org/10.1016/j.ijhcs.2019.05.002

[9] V. Venkatesh, J. Y. L. Thong, and X. Xu, "Consumer acceptance and use of information technology: extending the unified theory of acceptance and use of technology," MIS Q., vol. 36, no. 1, pp. 157-178, 2012. https://doi.org/10.2307/41410412

[10] R. H. Abu-Ghosh, D. H., Al-Dmour, H., Alalwan, A. A., \& Al-Dmour, "Factors Affecting Jordanian Consumers' Attitudes Towards Facebook Advertising: Case Study of Tourism," Emerg. Mark. from a Multidiscip. Perspect. Springer., pp. 285-302, 2018. https://doi.org/10.1007/978-3-319-75013-2_22 
[11] M. S. Talukder, G. Sorwar, Y. Bao, J. U. Ahmed, and M. A. S. Palash, "Predicting antecedents of wearable healthcare technology acceptance by elderly: A combined SEMNeural Network approach," Technol. Forecast. Soc. Change, vol. 150, p. 119793, 2020. https://doi.org/10.1016/j.techfore.2019.119793

[12] Y. Yang and X. Wang, "Modeling the intention to use machine translation for student translators: An extension of Technology Acceptance Model," Comput. Educ., vol. 133, pp. 116-126, 2019. https://doi.org/10.1016/j.compedu.2019.01.015

[13] N. Briggs, "Neural Machine Translation Tools in the Language Learning Classroom: Students' Use, Perceptions, and Analyses.," JALT CALL J., vol. 14, no. 1, pp. 2-24, 2018.

[14] S. Doherty and D. Kenny, "The design and evaluation of a statistical machine translation syllabus for translation students," Interpret. Transl. Train., vol. 8, no. 2, pp. 295-315, 2014. https://doi.org/10.1080/1750399x.2014.937571

[15] B. M. Gupta and S. M. Dhawan, "Machine Translation Research A Scientometric Assessment of Global Publications Output during 2007 16," DESIDOC J. Libr. Inf. Technol., vol. 39, no. 1, pp. 31-38, 2019. https://doi.org/10.14429/djlit.39.1.13558

[16] S. Papadakis, M. Kalogiannakis, E. Sifaki, and N. Vidakis, "Evaluating Moodle use via Smart Mobile Phones. A case study in a Greek University.," EAI Endorsed Trans. Creat. Technol., vol. 5, no. 16, p. e1, 2018. https://doi.org/10.4108/eai.10-4-2018.156382

[17] J. A. Bargas-Avila and K. Hornbæk, "Old wine in new bottles or novel challenges: a critical analysis of empirical studies of user experience," in Proceedings of the SIGCHI conference on human factors in computing systems, 2011, pp. 2689-2698. https://doi.org/10.1145/1978942.1979336

[18] R. Latikka, T. Turja, and A. Oksanen, "Self-efficacy and acceptance of robots," Comput. Human Behav., vol. 93, pp. 157-163, 2019. https://doi.org/10.1016/j.chb.2018.12.017

[19] C.-L. Hsu and H.-P. Lu, "Why do people play on-line games? An extended TAM with social influences and flow experience," Inf. Manag., vol. 41, no. 7, pp. 853-868, 2004. https://doi.org/10.1016/j.im.2003.08.014

[20] S. J. Czaja et al., "Factors predicting the use of technology: findings from the Center for Research and Education on Aging and Technology Enhancement (CREATE).," Psychol. Aging, vol. 21, no. 2, p. 333, 2006. https://doi.org/10.1037/0882-7974.21.2.333

[21] W. Ming-Yen Teoh, S. Choy Chong, B. Lin, and J. Wei Chua, "Factors affecting consumers' perception of electronic payment: an empirical analysis," Internet Res., vol. 23, no. 4, pp. 465-485, 2013. https://doi.org/10.1108/intr-09-2012-0199

[22] S.-C. Chen, H.-H. Chen, and M.-F. Chen, "Determinants of satisfaction and continuance intention towards self-service technologies," Ind. Manag. Data Syst., vol. 109, no. 9, pp. 1248-1263, 2009. https://doi.org/10.1108/02635570911002306

[23] P. Ifinedo, "Examining students' intention to continue using blogs for learning: Perspectives from technology acceptance, motivational, and social-cognitive frameworks," Comput. Human Behav., vol. 72, pp. 189-199, 2017. https://doi.org/10.1016/j.chb.2016.12.049

[24] J. Schikofsky, T. Dannewald, and M. Kowald, "Exploring motivational mechanisms behind the intention to adopt mobility as a service (MaaS): Insights from Germany," Transp. Res. Part A Policy Pract., 2019. https://doi.org/10.1016/j.tra.2019.09.022

[25] G. Hofstede, Culture's consequences: Comparing values, behaviors, institutions and organizations across nations. Sage publications, 2001. https://doi.org/10.2307/3556622

[26] A. Tarhini, K. Hone, and X. Liu, "A cross-cultural examination of the impact of social, organisational and individual factors on educational technology acceptance between B ritish and L ebanese university students," Br. J. Educ. Technol., vol. 46, no. 4, pp. 739-755, 2015. https://doi.org/10.1111/bjet.12169 
[27] T. Teo, F. Huang, and C. K. W. Hoi, "Explicating the influences that explain intention to use technology among English teachers in China," Interact. Learn. Environ., vol. 26, no. 4, pp. 460-475, 2018. https://doi.org/10.1080/10494820.2017.1341940

[28] F. Huang, T. Teo, J. C. Sánchez-Prieto, F. J. García-Peñalvo, and S. Olmos-Migueláñez, "Cultural values and technology adoption: A model comparison with university teachers from China and Spain,” Comput. Educ., vol. 133, pp. 69-81, 2019. https://doi.org/10.1016/j.compedu.2019.01.012

[29] L. Stoel and K. Hye Lee, "Modeling the effect of experience on student acceptance of Webbased courseware," Internet Res., vol. 13, no. 5, pp. 364-374, 2003. https://doi.org/10.1108/10662240310501649

[30] D. Y. Lee and M. R. Lehto, "User acceptance of YouTube for procedural learning: An extension of the Technology Acceptance Model," Comput. Educ., vol. 61, no. 1, pp. 193208, 2013. https://doi.org/10.1016/j.compedu.2012.10.001

[31] D. C. Yen, C.-S. Wu, F.-F. Cheng, and Y.-W. Huang, "Determinants of users' intention to adopt wireless technology: An empirical study by integrating TTF with TAM," Comput. Human Behav., vol. 26, no. 5, pp. 906-915, 2010. https://doi.org/10.1016/j.chb.2010.02. $\underline{005}$

[32] C. L. Chuan and J. Penyelidikan, "Sample size estimation using Krejcie and Morgan and Cohen statistical power analysis: A comparison," J. Penyelid. IPBL, vol. 7, pp. 78-86, 2006.

[33] J. C. Nunnally and I. H. Bernstein, "Psychometric theory," 1978.

[34] M. Al-Emran and S. A. Salloum, "Students' Attitudes Towards the Use of Mobile Technologies in e-Evaluation," Int. J. Interact. Mob. Technol., vol. 11, no. 5, pp. 195-202, 2017. https://doi.org/10.3991/ijim.v11i5.6879

[35] C. M. Ringle, S. Wende, and J.-M. Becker, "SmartPLS 3. Bönningstedt: SmartPLS.” 2015.

[36] J. Hair, C. L. Hollingsworth, A. B. Randolph, and A. Y. L. Chong, "An updated and expanded assessment of PLS-SEM in information systems research," Ind. Manag. Data Syst., vol. 117, no. 3, pp. 442-458, 2017. https://doi.org/10.1108/imds-04-2016-0130

[37] N. Urbach and F. Ahlemann, "Structural equation modeling in information systems research using partial least squares," J. Inf. Technol. theory Appl., vol. 11, no. 2, pp. 5-40, 2010.

[38] J. F. Hair Jr, G. T. M. Hult, C. Ringle, and M. Sarstedt, A primer on partial least squares structural equation modeling (PLS-SEM). Sage Publications, 2016. https://doi.org/10.3926/oss.37

[39] D. L. Goodhue, W. Lewis, and R. Thompson, "Does PLS have adavantages for small sample size or non-normal data?," MIS Quaterly, 2012. https://doi.org/10.2307/41703490

[40] D. Barclay, C. Higgins, and R. Thompson, The Partial Least Squares (pls) Approach to Casual Modeling: Personal Computer Adoption Ans Use as an Illustration. 1995.

[41] J. C. Nunnally and I. H. Bernstein, Psychometric theory. 1994.

[42] R. B. Kline, Principles and practice of structural equation modeling. Guilford publications, 2015.

[43] C. Fornell and D. F. Larcker, "Evaluating Structural Equation Models With Unobservable Variables and Measurement Error," J. Mark. Res., vol. 18, no. 1, pp. 39-50, 1981. https://doi.org/10.1177/002224378101800104

[44] J. Henseler, C. M. Ringle, and M. Sarstedt, "A new criterion for assessing discriminant validity in variance-based structural equation modeling," J. Acad. Mark. Sci., vol. 43, no. 1, pp. 115-135, 2015. https://doi.org/10.1007/s11747-014-0403-8

[45] A. E. Dreheeb, N. Basir, and N. Fabil, "Impact of System Quality on Users' Satisfaction in Continuation of the Use of e-Learning System," Int. J. e-Education, e-Business, eManagement e-Learning, vol. 6, no. 1, p. 13, 2016. https://doi.org/10.17706/ijeeee.2016.6.1.13-20 
[46] M. Alshurideh, S. A. Salloum, B. Al Kurdi, and M. Al-Emran, "Factors affecting the Social Networks Acceptance: An Empirical Study using PLS-SEM Approach," in 8th International Conference on Software and Computer Applications, 2019. https://doi.org/10.1145/3316615.3316720

[47] J. F. Hair Jr, G. T. M. Hult, C. Ringle, and M. Sarstedt, A primer on partial least squares structural equation modeling (PLS-SEM). Sage Publications, 2016. https://doi.org/10.3926/oss.37

[48] M. Senapathi and A. Srinivasan, "An empirical investigation of the factors affecting agile usage," in Proceedings of the 18th international conference on evaluation and assessment in software engineering, 2014, p. 10. https://doi.org/10.1145/2601248.2601253

[49] W. W. Chin, "The partial least squares approach to structural equation modeling," Mod. methods Bus. Res., vol. 295, no. 2, pp. 295-336, 1998.

[50] M. Tenenhaus, V. E. Vinzi, Y.-M. Chatelin, and C. Lauro, "PLS path modeling," Comput. $\begin{array}{lllllll}\text { Stat. Data Anal., vol. 48, no. 1, pp. 159-205, } 2005 . & \end{array}$ https://doi.org/10.1016/j.csda.2004.03.005

[51] M. Wetzels, G. Odekerken-Schröder, and C. Van Oppen, "Using PLS path modeling for assessing hierarchical construct models: Guidelines and empirical illustration," MIS Q., pp. 177-195, 2009. https://doi.org/10.2307/20650284

[52] B. Efron and R. J. Tibshirani, "The jackknife," in An introduction to the bootstrap, Springer, 1993, pp. 141-152. https://doi.org/10.1007/978-1-4899-4541-9_11

[53] S. A. Salloum, A. Q. M. Alhamad, M. Al-Emran, A. A. Monem, and K. Shaalan, "Exploring Students' Acceptance of E-Learning Through the Development of a Comprehensive Technology Acceptance Model," IEEE Access, vol. 7, pp. 128445-128462, 2019. https://doi.org/10.1109/access.2019.2939467

[54] S. A. Salloum, M. Al-Emran, R. Khalaf, M. Habes, and K. Shaalan, "An Innovative Study of E-Payment Systems Adoption in Higher Education: Theoretical Constructs and Empirical Analysis.," Int. J. Interact. Mob. Technol., vol. 13, no. 6, 2019. https://doi.org/ $\underline{10.3991 / \text { ijim.v13i06.9875 }}$

[55] S. A. Salloum and M. Al-Emran, "Factors affecting the adoption of e-payment systems by university students: extending the TAM with trust," Int. J. Electron. Bus., vol. 14, no. 4, pp. 371-390, 2018. https://doi.org/10.1504/ijeb.2018.10019536

[56] M. T. Alshurideh, S. A. Salloum, B. Al Kurdi, A. A. Monem, and K. Shaalan, "Understanding the Quality Determinants that Influence the Intention to Use the Mobile Learning Platforms: A Practical Study," Int. J. Interact. Mob. Technol., vol. 13, no. 11, pp. 157-183, 2019. https://doi.org/10.3991/ijim.v13i11.10300

[57] R. S. Al-Maroof, S. A. Salloum, A. Q. M. AlHamadand, and K. Shaalan, "A Unified Model for the Use and Acceptance of Stickers in Social Media Messaging," in International Conference on Advanced Intelligent Systems and Informatics, 2019, pp. 370-381. https://doi.org/10.1007/978-3-030-31129-2_34

[58] S. A. Salloum, M. Al-Emran, K. Shaalan, and A. Tarhini, "Factors affecting the E-learning acceptance: A case study from UAE," Educ. Inf. Technol., 2018. https://doi.org/10.1 007/s10639-018-9786-3

[59] S. A. Salloum and K. Shaalan, "Adoption of e-book for university students," in International Conference on Advanced Intelligent Systems and Informatics, 2018, pp. 481494. https://doi.org/10.1007/978-3-319-99010-1_44

[60] S. F. S. Alhashmi, S. A. Salloum, and S. Abdallah, "Critical Success Factors for Implementing Artificial Intelligence (AI) Projects in Dubai Government United Arab Emirates (UAE) Health Sector: Applying the Extended Technology Acceptance Model 
(TAM)," in International Conference on Advanced Intelligent Systems and Informatics, 2019, pp. 393-405. https://doi.org/10.1007/978-3-030-31129-2_36

[61] S. A. S. Salloum and K. Shaalan, 'Investigating students' acceptance of E-learning system in Higher Educational Environments in the UAE: Applying the Extended Technology Acceptance Model (TAM).” The British University in Dubai, 2018.

[62] P. Cadwell, S. Castilho, S. O'Brien, and L. Mitchell, "Human factors in machine translation and post-editing among institutional translators," Transl. Spaces, vol. 5, no. 2, pp. 222-243, 2016. https://doi.org/10.1075/ts.5.2.04cad

[63] M.-C. Tsai, Y.-Y. Chien, and C.-C. Cheng, "Upgrading service quality of mobile banking," Int. J. Mob. Commun., vol. 16, no. 1, pp. 82-115, 2018.

[64] J.-W. Lin and H.-C. K. Lin, "User acceptance in a computer-supported collaborative learning (CSCL) environment with social network awareness (SNA) support," Australas. $J$. Educ. Technol., vol. 35, no. 1, pp. 100-115, 2019. https://doi.org/10.14742/ajet.3395

[65] M. Kalogiannakis and S. Papadakis, "Evaluating a Course for Teaching Advanced Programming Concepts with Scratch to Preservice Kindergarten Teachers: A Case Study in Greece," in Early Childhood Education, IntechOpen, 2018. https://doi.org/10.5772/ intechopen.81714

[66] R. A. Carels et al., "Using an acceptance-based behavioral approach as a supplement to obesity treatment: A stepped-care approach," J. Context. Behav. Sci., vol. 12, pp. 98-105, 2019.

[67] L. Monacis, F. Ceglie, P. Limone, G. Tanucci, and M. Sinatra, "EXPLORING INDIVIDUAL DIFFERENCES AMONG TEACHERS'ICT ACCEPTANCE: A PATH MODEL AND THE ROLE OF EXPERIENCE.," Hum. Technol., vol. 15, no. 2, 2019. https://doi.org/10.17011/ht/urn.201906123159

[68] C.-H. Chen, C.-Y. Huang, and Y.-Y. Chou, "Effects of augmented reality-based multidimensional concept maps on students' learning achievement, motivation and acceptance," Univers. Access Inf. Soc., vol. 18, no. 2, pp. 257-268, 2019. https://doi.org/10.1007/s10209-017-0595-z

[69] M. Shin, M. Moon, C. Lee, and S. Kwon, "Physical education affects adolescents' peer acceptance: Influence of gender and motivation climate," Soc. Behav. Personal. an Int. J., vol. 47, no. 4, pp. 1-11, 2019. https://doi.org/10.2224/sbp.7732

[70] V. Dutot, V. Bhatiasevi, and N. Bellallahom, "Applying the technology acceptance model in a three-countries study of smartwatch adoption," J. High Technol. Manag. Res., 2019. https://doi.org/10.1016/j.hitech.2019.02.001

[71] V. Venkatesh and H. Bala, "Technology Acceptance Model 3 and a Research Agenda on Interventions," Decis. Sci., vol. 39, no. 2, pp. 273-315, 2008. https://doi.org/10.1111/j.1540$\underline{5915.2008 .00192 . x}$

[72] G. Hofstede and G. J. Hofstede, "Cultures and organizations: software of the mind (Revised and expanded 2nd ed.)," New York, 2005.

[73] C. Yoon, "The effects of national culture values on consumer acceptance of e-commerce: Online shoppers in China," Inf. Manag., vol. 46, no. 5, pp. 294-301, 2009. https://doi.org/10.1016/j.im.2009.06.001 


\section{Authors}

Rana A. Saeed is specialized in English Language and linguistics and interested in e-learning and its acceptance and adoption. Currently employed at "Al-Buraimi University College" in Oman, assistant professor in the "English Department".

Said A. Salloum had graduated from The British University in Dubai with a distinction with MSc in Informatics (Knowledge and Data Management). He got his Bachelor's degree in Computer Science from Yarmouk University. Currently, He is working at the University of Sharjah "Research Institute of Sciences and Engineering (RISE)" as a researcher on different research areas in Computer Science such as data analysis, machine learning, knowledge management, and Arabic Language Processing. Salloum is an Oracle expert since 2013 along with various recognized international certificates that are issued by Oracle.

Ahmad Qasim Mohammad AlHamad is an Assistant Professor at Abu Dhabi University, UAE. He had his $\mathrm{PhD}$ in Information Systems from Coventry University 2011. In addition, he got his MSc from Queen Margaret University at Edinburgh 2002. He has 19 years of teaching experience including being the Dean of IT College at Fujairah University, UAE for 3 years. His research interest focuses on the ebusiness (e-commerce, mobile commerce, and e learning). In addition, he is interested in the ethical, professional, and legal issues in computing. Furthermore, he is also interested in personalizing e-learning systems, which include dealing with expert systems. Some published work in students' privacy. Also, a paper was published in ehealth field. The latest research interest includes publishing three journals in data and text mining.

Dr. Khaled Shaalan is a full professor of Computer Science/Artificial Intelligence at the British University in Dubai (BUiD), UAE. He is an Honorary Fellow at the School of Informatics, University of Edinburgh (UoE), UK. Prof Khaled is an Associate Editor on ACM Transactions of Asian and Low Resource Language Information Processing ( $\underline{\text { TALLIP }})$ editorial board, Published by the Association for Computing Machinery ( $\underline{\mathrm{ACM}})$, USA.

Prof Khaled has a long experience in teaching in the field of Computer Science for both core and advanced undergraduate and postgraduate levels. He has taught 30+ different courses at the undergraduate and postgraduate levels.

Over the last two decades, Prof Khaled has been contributing to a wide range of research topics in Arabic Natural Language Processing, including machine translation, parsing, spelling and grammatical checking, named entity recognition, and diacritization. Moreover, he has also worked on topics in knowledge management, knowledgebased systems, knowledge engineering methodology, including expert systems building tools, expert systems development, and knowledge verification. Nevertheless, Khaled worked on health informatics topics, including context-aware knowledge modelling for decision support in E-Health and game-based learning. Furthermore, Prof Khaled worked in educational topics, including intelligent tutoring, item banking, distance learning, and mobile learning. He has been the principal investigator or co-investigator on research grants from USA, UK, and UAE funding bodies. 
Prof Khaled has published over 180+ referred publications and the impact of his

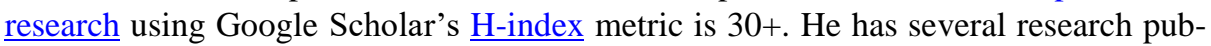
lications in his name in highly reputed journals such as Computational Linguistics, Journal of Natural Language Engineering, Journal of the American Society for Information Science and Technology, IEEE Transactions on Knowledge and Data Engineering, Expert Systems with Applications, Software-Practice \& Experience, Journal of Information Science, Computer Assisted Language Learning, and European Journal of Scientific Research to name a few. Prof Khaled's research work is cited extensively worldwide (see his Google Scholar citation indices). He has guided several Doctoral and Master Students in the area of Arabic Natural Language Processing, Healthcare, Education Technology, and Knowledge Management. Prof Khaled encourages and supports his students in publishing at highly ranked journals and conference proceedings.

Prof. Khaled has been actively and extensively supporting the local and international academic community. He is the founder and Co-Chair of The International Conference on Arabic Computational Linguistic (ACLing). He is the editor of many books published by Springer. He has participated in seminars, invited talks locally, and internationally, invited to international group meetings, invited to review papers from leading conferences and premier journals in his field, and invited for reviewing promotion applications to the ranks of Associate and Full Professor for applicants from both British and Arab Universities. Prof Khaled is the Head of Programmes, $\mathrm{PhD}$ in Computer Science, MSc in Informatics and MSc in IT Management, and BSc in Computer Science (Artificial Intelligence, Software Engineering).

Article submitted 2019-06-25. Resubmitted 2019-12-05. Final acceptance 2019-12-05. Final version published as submitted by the authors. 